\title{
BMJ Open How older citizens engage in their health promotion: a qualitative research-driven taxonomy of experiences and meanings
}

\author{
Julia Menichetti, Guendalina Graffigna
}

To cite: Menichetti J, Graffigna G. How older citizens engage in their health promotion: a qualitative research-driven taxonomy of experiences and meanings. BMJ Open 2016;6:e010402. doi:10.1136/bmjopen-2015010402

- Prepublication history for this paper is available online. To view these files please visit the journal online (http://dx.doi.org/10.1136/ bmjopen-2015-010402).

Received 30 October 2015 Revised 12 April 2016 Accepted 14 April 2016
CrossMark

Department of Psychology, Università Cattolica del Sacro Cuore, Milano, Italy

\section{Correspondence to} Professor Guendalina Graffigna; guendalina. graffigna@unicatt.it

\section{ABSTRACT}

Objectives: In this qualitative study, we provide an indepth exploration of older people's experiences and subjective meanings concerning their engagement in health promotion as well as the emotional and pragmatic difficulties they face during their engagement.

Methods: The study was designed according to the ethnoscience method, which implies a participatory process that values patients' linguistic expressions to deeply understand the phenomena under the investigation and to give it a meaning. Using this method, thanks to repeated rounds of interviews and the Q-sorting task, participants created a dictionary, with the assistance of the researcher, to describe the phenomenon of interest. They agreed on a shared taxonomy of meanings and experiences related to the phenomenon. 25 North Italian older citizens participated in this study.

Results: Participants described a shared taxonomy of health engagement experiences by depicting 3 main positions (ie, locked position; awakening position; climbing position), which represented different experiential domains grouped by participants into 4 main semantic areas (eg, physical care, soul care, daily lifestyle, contact with ageing). Each position is characterised by specific emotions, personal representations of meaning and healthy behaviours that may sustain or hinder older citizens' engagement in health promotion.

Conclusions: The results of the present study suggest the importance of deeply understanding older peoples' experiences and their subjective meanings of health promotion. In particular, the results showed how their engagement in health promotion is framed in a complex system of psychological meanings, which may sustain or hinder their ability to adopt healthy behaviours. A deeper understanding of older citizens' lived experiences, their doubts and their difficulties in engaging in health promotion may offer some important cues for orienting interventions in this area.

\section{INTRODUCTION}

Societies worldwide are facing an increasingly ageing population because of the rapid

\section{Strengths and limitations of this study}

- To the best of our knowledge, this is the first qualitative study investigating older citizens' experiences, motivations and attitudes towards their health promotion.

- The ethnoscience method allowed us to unveil subjective meanings of older citizens' health promotion experiences.

- The ethnoscience method also allowed us to adopt a truly participative process of research where older citizens collaborated with the researchers in the construction of a shared vocabulary and taxonomy of their health promotion experiences.

- These qualitative evidences cast light on subjective meanings and experiences that may sustain or hinder older citizens' engagement in their health promotion.

- Our study is limited by a locally selected sample.

decline in mortality in the past few decades due to scientific and technological progress. ${ }^{1}$ In Italy, life expectancy has increased by 2 years in the past 10 years; however, people actually live the last third of their lives with at least one chronic condition. ${ }^{2}$ The rapid growth of the ageing population poses important challenges, specifically those related to the health of older people. ${ }^{3}$ Most societies need to promote healthy behaviours, prevent diseases, and develop effective and ecological low-cost strategies to effectively manage healthcare burdens associated with the ageing of the population. ${ }^{4}$ In the literature, different theoretical models have been developed with the aim of promoting health behaviour changes in patients/citizens, working at individual, interpersonal or community levels. For example, looking at the individual level, the health belief model, which has been widely adopted, recognises the importance of people's beliefs about health problems, perceived benefits of and barriers to action, cues 
to action and self-efficacy in explaining engagement in health-promoting behaviours. ${ }^{5-7}$ Differently, the transtheoretical model conceives behaviour change as a process comprising five levels of readiness to change (ie, precontemplation, contemplation, preparation, action and maintenance) through which individuals progress to adopt healthy or eliminate unhealthy behaviours. ${ }^{8}$ Additionally, the social cognitive theory was adopted at individual and interpersonal levels to understand the ways in which personal cognitive factors (eg, self-efficacy, observational learning, expectations) can represent a third interface between individual and social environment that can sustain behaviour change..$^{9}$ Similarly, the theory of planned behaviour links beliefs to health behaviours and suggests the ways in which behaviours, subjective norms and perceived behavioural control together could shape an individual's behavioural intentions and thus behaviours. ${ }^{10}$ Most of these models, however, failed to consider cultural and age-related factors, which are needed to explain differences in health-promoting behaviours. ${ }^{11} 12$ Indeed, since older adults differ from younger cohorts in important ways in terms of their health status, living situation, well-being and educational level, ${ }^{13}{ }^{14}$ the investigation of the process of engagement in health promotion among older adults is likely to be useful when considering such differences. Consequently, studies on the determinants that, from an individual perspective, may sustain or hinder the engagement of older citizens in health promotion by giving voice to older citizens' experiences are needed. ${ }^{15-17}$

The goal of this study was to provide an in-depth understanding of older citizens' experiences with health promotion, with a particular reference to the subjective meanings and elements that-from older citizens' perspective-may favour or hinder such experiences. On the basis of these premises, the aims of the study were twofold:

- To involve older citizens in a participatory research process aimed at drafting a shared taxonomy of meanings and representation related to their health promotion experience.

- To deepen factors of older citizens' experiences that may sustain or hinder their engagement in health promotion.

Following the recent activities of the European Union on ageing, ${ }^{18}$ we aspire to provide the knowledge base for the promotion of appropriate strategies and interventions to enhance older citizens' engagement in health promotion and improve their life conditions by deliberately focusing on a particular age group (older people younger than 75 years), which could particularly benefit from health promotion initiatives, as they are in most cases still fit, active and able to care for themselves. Consequently, improving healthy habits in this subgroup of older citizens may be more doable, as well as prevent negative clinical situations. ${ }^{19}$ It is not surprising that most preventive measures and health promotion initiatives focused on this 'younger' age group to stave off health-related problems in the next decades. ${ }^{20} 21$

\section{METHODS \\ Design}

A qualitative study designed according to the ethnoscience method ${ }^{22}$ was adopted to involve older citizens in the construction of a common vocabulary and in a shared taxonomy related to their health management experiences. This method assumes the importance of studying language (and the way language is used) to understand implicit meanings related to individual experiences. The linguistic choices made by speakers when describing their health management attitudes and behaviours may indeed uncover the social representations, emotional experiences and psychological attitudes of people towards their health. This may be particularly meaningful when the phenomenon under investigation is complex and 'abstract' (such as discussing about one's own engagement in health promotion) and when interviewees may find it difficult to reflect deeply on their related experiences. Ethnoscience is based on repeated semistructured interviews and Q-sorting tasks to allow the flexible investigation of the phenomena under investigation and to study the lexical expressions of participants when describing their experiences (see Data collection and procedure section).$^{23}$ The Q-sorting technique is a general methodology used to gather and process a person's viewpoint as well as to categorise a complex phenomenon. ${ }^{24}$ By Q-sorting, people reveal their individual way of categorising a phenomenon and giving sense to a particular reality. ${ }^{25}{ }^{26}$ In detail, all interviewees were interviewed twice. In the first round, they were required to reflect on their health promotion experiences following a semistructured guide of interview and a non-directive moderation style. In the second round of interviews, they were asked to engage in a participative analysis process aimed at drafting a shared vocabulary and taxonomy of health promotion experiences thanks to Q-sort tasks. In particular, the tasks involved selecting cards (which reported linguistic extracts from previous interviews) that reflected their health promotion experience, grouping the selected cards, assigning a name to each group, reflecting on the relationships among groups, and providing insights on the factors that are able to foster/obstruct older people's health promotion experiences (see the next paragraph for further details).

\section{Data collection and procedure}

Participants were involved in two sequential rounds of semistructured interviews. Two researchers conducted the interviews together. Both of them were psychologists trained in qualitative methods.

- The first round of interviews posed broad questions to collect data on the meanings and representations of health promotion, concrete daily habits, 
engagement in healthy lifestyles and situations that foster or obstruct active engagement in health promotion (see table 1 for details). Additional questions were asked, when needed, to elicit further details. Questions posed by researchers who adopt the ethnoscience method are usually broad and open-ended to elicit narratives from the participants and collect all possible statements, opinions and experiences from the respondents about the phenomenon under investigation. ${ }^{27}$ All interviews were fully transcribed, and selected recurrent linguistic expressions used by interviewees to describe their health promotion experience were reported verbatim on cards: one linguistic expression per card (see the Data analysis section for further details).

- All interviewees were reinterviewed after the first phase of the data analysis to construct a shared taxonomy of their health promotion experiences in collaboration with the researchers. In particular, this second round of interviews implied Q-sorting tasks. The first Q-sorting task asked participants to select the meanings and linguistic expressions reported on the cards that best represented their experience and engagement in health promotion (ie, please select the cards that mainly represent you) and to eliminate the cards which they felt were far from their subjective experience. In the second task, participants were invited to group and categorise the selected cards based on spontaneously agreed on homogeneity criteria (Among the cards you selected, can you identify group of cards that can be linked together?). This second task allowed the investigation of spontaneous categorisation and thus of individuals' representational domains. This task formed the basis of the first 'taxonomies of meanings' spontaneously created by participants during their interviews (How do the groups of cards relate among them? What is the reason of these linkages? What do this emerging taxonomy means to you?).

Each interview was completed in the individual's home or at the participant's place of preference. The interviews ranged from 40 to $90 \mathrm{~min}$, with an average duration of $60 \mathrm{~min}$.

\section{Participants}

A purposive sample of 25 North Italian older adults was sequentially recruited to participate in the study. ${ }^{28}$ Potential participants were recruited through several means. First, citizens were recruited from different senior centres (eg, community centres, activity centres, recreation associations, community recreation centres), which were contacted by telephone or email, and invited to take part in the study. Individuals with the desired characteristics were then asked to recommend similar participants from their social networks, starting a "process analogous to a snowball rolling down a hill'. ${ }^{29}{ }^{30}$ Thus, a snowball sampling technique was adopted, ${ }^{31}$ which is particularly useful to reach vulnerable or hard-to-reach groups in a more effective, pragmatic and culturally competent way. ${ }^{29}$ The inclusion criteria were:

1. Being 65-75 years of age (this range was selected because people who are younger than 75 years of age may particularly benefit from engaging in healthpromoting behaviours in terms of prevention of future health problems; furthermore, this target population is more likely to engage in health promotion initiatives compared with individuals older than 75 years of age);

2. Being able to express themselves with well-articulated stories and to deeply reflect on their stories (eg, people with mental health problems or impaired physical conditions were excluded);

3. Being able to understand and speak Italian;

4. Being willing to participate in the study.

Table 1 First round of interviews' guide

\begin{tabular}{|c|c|}
\hline Area & Questions \\
\hline $\begin{array}{l}\text { Meanings and representations of health } \\
\text { and health promotion }\end{array}$ & $\begin{array}{l}\text { 1. Let's introduce what health means to you ... let's describe this using your } \\
\text { words. }\end{array}$ \\
\hline Concrete daily actions to promote health & 2. What does promoting health mean to you? \\
\hline \multirow{2}{*}{$\begin{array}{l}\text { Feelings, thoughts, behaviours when } \\
\text { thinking of health promotion }\end{array}$} & 3. Could you describe to me your lifestyle in the past week? \\
\hline & 4. How do you manage your health daily? \\
\hline \multirow[t]{5}{*}{$\begin{array}{l}\text { Perspectives and experiences of } \\
\text { engagement in health promotion }\end{array}$} & $\begin{array}{l}\text { 5. Could you describe a real situation where you promoted your health? What } \\
\text { happened and what have you done? Why? Who were the actors? Have you } \\
\text { involved someone? When you healed, you managed health in the same } \\
\text { way? }\end{array}$ \\
\hline & $\begin{array}{l}\text { 6. What are your feelings and thoughts when you reflect on how you are } \\
\text { promoting your health? What can you do to improve your health? }\end{array}$ \\
\hline & 7. In your opinion, why are people engaged differently in their health \\
\hline & $\begin{array}{l}\text { 8. Do you think that it is possible to become more or less engaged in health } \\
\text { promotion? How? Could you describe to me some situation or event that } \\
\text { changed your engagement? }\end{array}$ \\
\hline & 9. What would help you in being more engaged in promoting your health? \\
\hline
\end{tabular}




\section{Data analysis}

All interviews were transcribed verbatim and analysed using thematic analysis with an inductive approach. ${ }^{32}$ Two researchers analysed and coded the transcripts independently to identify the key words, phrases and expressions which the participants repeatedly used to describe their health promotion experiences. In a joint meeting, the researchers discussed and reached an agreement on a list of selected linguistic expressions. This process resulted in a shared 'dictionary' containing words/phrases that were then printed onto cards to be used in the second phase of the research process: the Q-sort tasks. These tasks were completed during the second round of interviews. The researchers kept track of card-sorting choices made by each participant during the second round of interviews. On the basis of spontaneous card sorting and grouping by each participant, researchers were able to draft a taxonomy of meanings and experiences (one for each participant), presenting the results of the card sorts in a tabular form. In a separate meeting, the researchers compared the taxonomies derived from the card-sort tasks to identify common thematic patterns and to develop a final, inclusive and synthetic taxonomy of older citizens' health promotion experiences. When disagreement emerged, the researchers reached a consensus through discussion.

The results are reviewed below, and they include some quotes extracted from the interviews to support our results. The researchers involved in the data collection and analysis translated the quotes selected for this article into English together with the assistance of an Italianspeaking and English-speaking translator. ${ }^{33}$ Finally, a professional native English translator corrected and checked the translations. ${ }^{33}$ Original quotes are available on request.

\section{Ethical concerns}

Each participant was free to participate and withdraw from the research and was informed about the procedures of the study. All participants consented to participate in the study (including audiotaping and transcription of the interviews) by signing a written consent form. Information that could identify participants was removed, and each interviewee was assigned an identification number to protect his/her anonymity.

\section{Findings}

Thirteen females and 12 males who met the inclusion criteria were included in the study. Most participants lived predominantly in Lombardy $(68 \%)$ and in villages or small towns of suburban areas $(60 \%)$ while only seven lived in Liguria (28\%). The age ranged from 65 to 75 years (mean age of 67.8 years). The sample comprised primarily retired participants. Overall, 23 participants resided with a family member (in most cases with their spouse/partner) and 7 of them lived with two or more family members (generally the husband/wife and adult children). Two older adult participants lived alone but near a family member. For further details, see table 2.

Interviews conducted using the ethnoscience method allowed us to draw a taxonomy of older people's experiences of health promotion. In particular, this taxonomy featured three different types of health promotion experiences (ie, locked position; awakening position; climbing position), which represented four main experiential domains (ie, see figure 1). Each position reflects specific representations, emotions, behaviours and subjective meanings. First, we summarised the semantic areas and experiential domains related to health promotion experiences of the older North Italian adults enrolled in the study that emerged from the interviews (ie, see figure 2). Thereafter, the taxonomies related to the three types of health promotion experiences that emerged from working collaboratively with interviewees are presented below (ie, see figure 1).

\section{Older citizens' experiences of health promotion: main domain of subjective meanings}

The following four main semantic areas emerged from the older citizens' accounts of their health promotion experiences.

Physical care: For older participants, promoting health and well-being evoked experiences of care of their physical body. Thus, emotions related to becoming sick, being adherent to medical prescriptions and to health checks, and having in mind that managing one's own health and preventing future health problems is a daily and crucial effort were important experiential domains of taking care of their physical health.

I'd name this group 'contact with my health', that is the contact with my body and with the awareness about the possibility that it could become sick.

(Interview 14, male, 70 years old)

\begin{tabular}{lcc} 
Table 2 Overview of the composition of the sample \\
\hline Features & $\mathbf{n}$ & Per cent \\
\hline Gender & & \\
$\quad$ Female & 13 & 52 \\
$\quad$ Male & 12 & 48 \\
Marital status & & \\
$\quad$ Married & 23 & 92 \\
$\quad$ Not married & 2 & 8 \\
Employment & & \\
$\quad$ Worker & 8 & 32 \\
$\quad$ Not worker & 17 & 68 \\
Domicile & & \\
$\quad$ Lombardia & 17 & 68 \\
$\quad$ Liguria & 8 & 32 \\
Geographic location & & \\
$\quad$ Urban & 7 & 60 \\
$\quad$ Suburban & 15 & 12 \\
$\quad$ Rural & 3 & \\
\hline
\end{tabular}




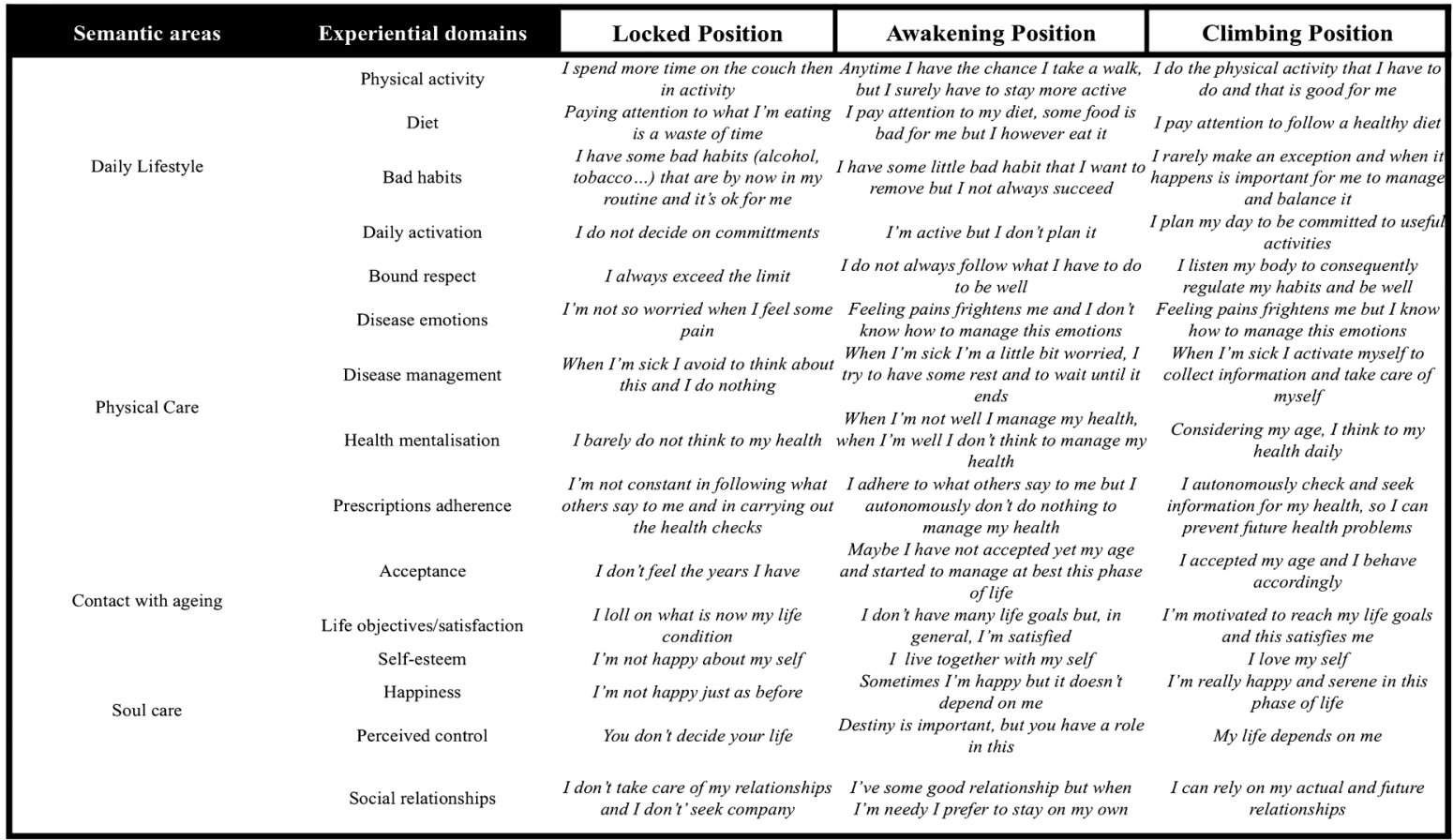

Figure 1 Taxonomy of older citizens' experiences of health promotion.

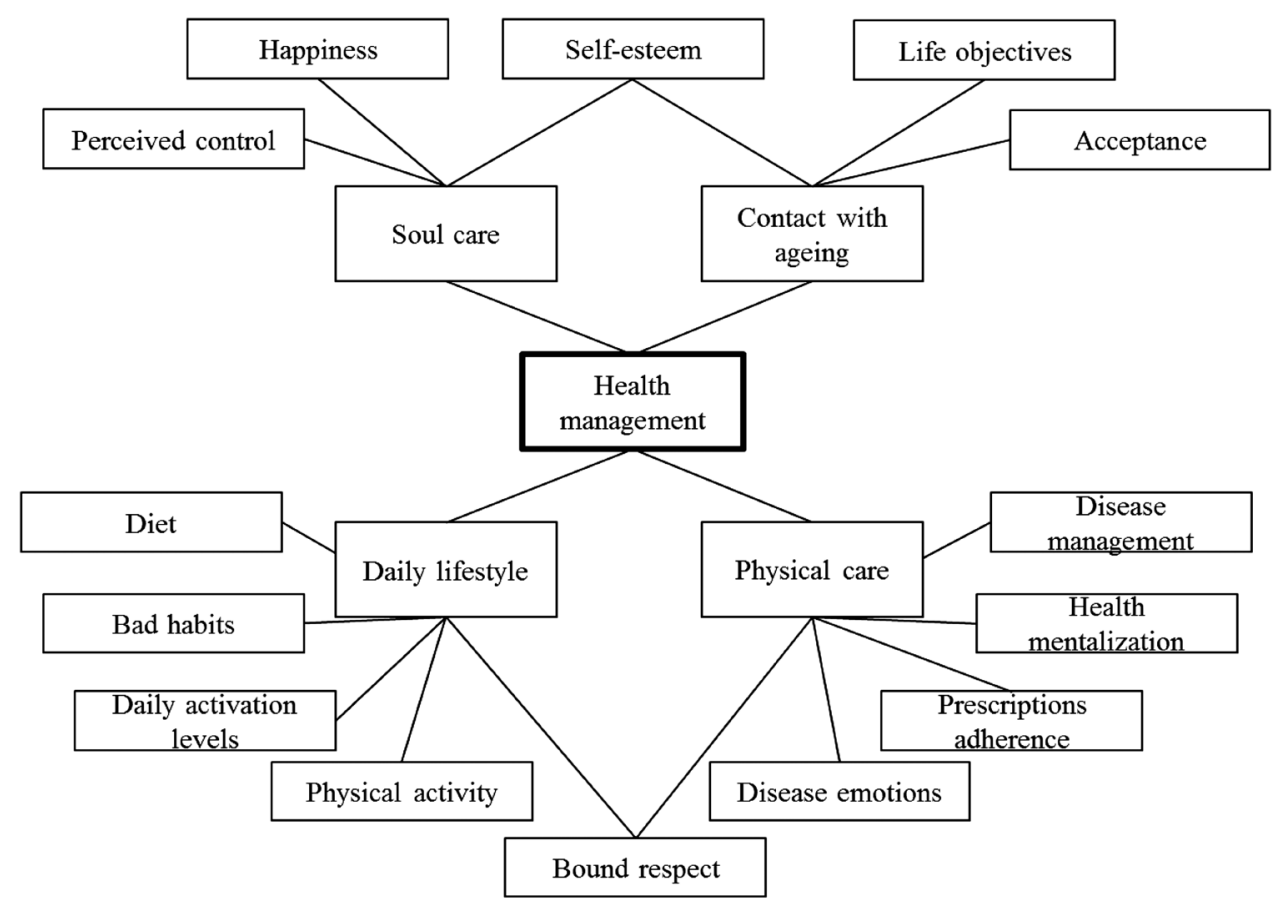

Figure 2 Semantic areas and domains of subjective meanings of older citizens' experiences with health promotion.

Daily lifestyle. Participants referred to this area when speaking about daily lifestyles, including factors such as physical activity, diet and risk behaviours (alcohol, smoke). In their words, "daily habits are the litmus test of my health, of my life" (interview 14, male, 73 years old). Participants also considered respect and awareness of limits, rules and boundaries as important when engaging in the suggested health-promoting behaviours and when effectively promoting health through physical care.

This group speaks about activities of everyday life to manage my health, how to do sport, eat ... how can we call it: lifestyle?

(Interview 20, male, 68 years old) 
Contact with ageing: Participants referred to 'being in contact with ageing' or 'living and perceiving ageing' to define the relationship with their age and their capacity to take the best from ageing. This domain of meanings also regards life objectives and the level of life satisfaction, the personal acceptance of ageing and the individual levels of self-esteem. Participants considered those factors as important in the successful ageing process and consequently in experiencing high levels of health and well-being.

It is also important how you live your age: how do you enjoy the present days? Are you in contact with your ageing?

(Interview 18, female, 65 years old)

Soul care: Finally, participants spoke about the importance of taking care of their mental health to support and promote their well-being. Participants described this area in terms of happiness, self-esteem and perceived control over life and health.

This is more a question of head, mental. It's how I feel at this moment and it's more a mental fact to love and accept myself and feel that life is in my hands ... of course, it takes a little bit of luck.

(Interview 15, female, 68 year old)

\section{Older citizens' experiences of health promotion: a taxonomy of experiences}

The analysis of all individual taxonomies produced by interviewees during the Q-sort tasks (and related to their subjective experience of health promotion) helped draft a final inclusive taxonomy of older citizens' health promotion experiences featuring three main positions described in detail in the following paragraphs.

\section{First position: 'I feel locked'}

Interviews revealed that the first experiential position of older citizens' health promotion was characterised by a blocked and frozen attitude towards health, which consequently leads to unhealthy lifestyles and habits. Lack of work and social network, emotional resignation, lack of purpose and unhealthy behaviours (ie, cigarettes, alcohol abuse) were found to characterise this position. Older participants often attributed the lack of healthy behaviours to a general lack of self-care and life purposes and used negative emotional words to refer to the relationship of this position with health. Participants reported a similar approach to health characterised by lack of love and self-acceptance, which often exemplifies the entire lifespan, although it is exacerbated by ageing-related issues (eg, retirement, death of loved ones, loss of a social role, menopause). Thinking about different ways to promote health during ageing was scary and anxiety provoking for people in this position; thus, 'continuing the life as usual', avoiding negative emotions and frightening thoughts that would emerge if health was in daily projects. This position was represented in terms of feeling 'locked' in an unhappy last part of life.

After all, my life is ok for me, so I do absolutely nothing to change it ... I'm fine by myself as well, so I don't really look for particular situations to increase what I should do to feel better.

(Interview 20, male, 65 years old)

I have an identity issue in organizing my health, I get anxious to thinking about it and I prefer to continue my life as usual.

(Interview 18, female, 65 years old)

Furthermore, the participants reported that health practices were inextricably linked to religious beliefs. Indeed, people in this position usually represented themselves as delegating their health management to others. Although this helped them avoid negative emotions, these beliefs contributed to the reduction of health promotion actions. Consequently, a fatalistic attitude with feelings of resignation and dissatisfaction with life was reported. These feelings also influenced the approach to risk prevention and health promotion. Regarding people in this position, the emergence of diseases could not be controlled; thus, following healthy lifestyles to prevent diseases would be useless.

It is useless to worry about what may happen and what can be done to prevent mishaps ... cancer or other diseases can occur also if you have an optimal lifestyle ...

(Interview 25, male, 68 years old)

Since the missing approach to health management was characterised by resignation, older participants reported that lack of purpose, worries and fears of losing autonomy or remaining alone were able to 'upset' and 'awake' them from the disengagement in health. The worries motivated them to seek sources of more positive feelings and hope towards future life trajectories.

I absolutely do not follow prevention, but if any serious illness came, I would be forced to change to regain my health.

(Interview 1, male, 65 years old)

You can change in the event that a disease hits you, so you become scared, so your lifestyle changes.

(Interview 20, male, 65 years old)

I stopped smoking thanks to a book that made me aware that depending on cigarettes made me miserable and that convinced me that having fun would help me.

(Interview 16, male, 73 years old)

\section{Second position: 'I'm awakening'}

Some other citizens, mostly with a good social network but without strong and supportive relationships, described themselves as alternating in managing health 
between health awareness and a lack of motivation to improve their health during ageing, with the general adoption of a healthy lifestyle without the awareness of risks due to ageing. Unlike the 'locked position', in the 'awakening position', older citizens alternated between a fatalistic and a more active attitude towards health and life, perceiving some situations as being under their control. People in this position represented themselves as caring about their health only when sick but lacked motivation and perceived loss of control over their health when recovering from the disease.

Obviously, I take care of my health when I'm sick to heal! But when I heal I do nothing to stay healthy: It's useless, it's not under your control!

\section{(Interview 10, female, 65 years old)}

Although participants in this position were aware of the importance of engaging in healthy behaviours, engaging in physical activities, eating better and planning meaningful activities to feel healthier, they preferred to leave health out of daily plans. Thus, they were described as aware but often inactive in managing and promoting health. Accordingly, they were classified as having an 'awakening' status. They described themselves as having understood the importance of engaging in healthy behaviours at the 'theoretical level', but in practice they reported failure to translate this knowledge into concrete health-promoting and health-preventive behaviours (eg, doing more physical activity, paying attention to diet, going to health checks). Furthermore, these older citizens often failed to recognise their actual need to 'do more' to improve their lifestyle, particularly because ageing requires greater attention to physical limits and to global self-care. Focusing on preventing and modifying their lifestyles according to the limitations and barriers that emerge during the process of ageing was perceived as highly connected to the acceptance of growing old and thus to the participants' experiences of ageing. Finally, a sort of emotive ambivalence towards their ageing process characterised this position. On the one hand, feelings of guilt for doing the bare minimum and, on the other hand, the desire to avoid being concerned with health increased the disconnect between actions and thoughts. In this sense, social relationships were conceived as useful in fostering a more active health engagement and planning daily habits among individuals in this position.

I know that I should do sport, in the past I used to go to the gym but in the recent years, I finally chose the oratory and not the gym, whereas I know that this is not the better choice for me.

(Interview 23, female, 68 years old)

Doing something with someone could help me to be more active.
Setting my own goals for the future and getting busy with daily commitment lead me to feel better...for example gardening or spending my time out, I'm sure that will bring benefit to my mind.

(Interview 24, male, 65 years old)

\section{Third position: 'I'm aware that I'm climbing'}

This experiential position was described in terms of a better integrated approach to health promotion. Important features of this position included being constantly aware of the importance of taking care of the self to remain healthy and feel good physically, mentally and socially. People in this position gave sense to their life and elaborated on the inevitability of death successfully, which allowed them to live fully every day. They were conscious that physical health influences well-being in all other spheres of human existence and that taking care of oneself increases wellness and happiness and fosters one's own sense of control over life trajectories. Thus, a strong sense of coherence, control and self-efficacy, as well as a greater motivation to feel aware and reflexive, emerged from the interviews as important factors of healthy ageing. In this sense, this position was defined as 'climbing' because of the constant efforts of participants to master their entire health status and well-being.

As I do something, I think about the consequence of what I'm doing to prevent diseases and how I'm feeling.

(Interview 3 , male, 75 years old)

At a certain age, you have to start thinking about your health and yourself, sooner or later something happens ... there is an exponential curve between age and health, and I'm at the point in which something will happen ... so I'm aware that I want to live the last years fully and peacefully!

(Interview 22, male, 75 years old)

Loving and accepting each other is the foundation of everything, it gives you a purpose of life, it makes you feel that it's you at the helm.

(Interview 14, male, 73 years old)

People in this position were represented as having successfully managed critical events (such as the occurrence of health problems or the deaths of friends and relatives) by elaborating their sense within the whole spectrum of their existence and in the light of a positive approach to life. People in this position shared the personal objective of contributing to the wealth of the world to have a sense of life and die peacefully. According to participants, being at peace with life, ageing and death fosters well-being and positive engagement in a healthy lifestyle.

Sooner or later, life ends. It is important to have the satisfaction of having done something, to have done things, to have left something ... more than the fear of death, I'd rather end in a particular way.

(Interview 22, male, 75 years old) 
The problem is not to avoid diseases but to live with them in a decent way and in line with your life.

(Interview 18, female, 65 years old)

These participants were described as believing that their own actions determine their health. Perceptions of having control over health and life foster, as older participants said, proactive behaviours and a sense of power and agency. Being able to face anxiety related to taking responsibility for their health status, having control over all health dimensions and strengthening feelings of selfdetermination were also important features of this position.

This is more a question of head, mental. It's how I feel at this moment and It's more a mental fact to love and accept myself and feel that life is in my hands ... of course it takes a little bit of luck.

(Interview 15, female, 68 year old)

Relationships also played an active part in the "climbing position' because playing an active social role in the community was conceived as a way to have a purpose in life and to be part of something bigger, which can give sense to life and death.

Sooner or later life ends, it is important to reach the satisfaction of having done something, of having left something, of having made a small contribution to other people ...

(Interview 22, male, 75 years old)

Additionally, participants explained their well-being as dependent also on "having the possibility to be free, also to exceed bounds sometimes" (interview 5, female, 67 years old). Indeed, engaging in bad habits is occasionally perceived as useful to maintain engagement in a balanced healthy lifestyle, avoiding the risk of becoming too obsessive about healthy behaviours and enjoying old age more fully.

\section{DISCUSSION}

This qualitative study explored older citizens' experiences of health promotion. Those experiences may be placed along a subjective continuum of engagement. One pole of the continuum represents the experiences of participants with lower levels of engagement, such as those who report resignation, inactivity and poor sense of agency and control over their health. The opposite pole represents the experiences of participants with high levels of engagement in their health promotion who described themselves as attentive, committed to adopt healthy ageing lifestyles and legitimate themselves as responsible for their physical and mental health promotion. These insights are in line with the results of a study on the effect of lay perspectives of the role of successful ageing in fostering personal and community well-being. ${ }^{34}$ This study, ${ }^{34}$ by emphasising the balance between self-contentment and self-growth in later life, suggested that reaching high levels of health engagement is related to higher levels of self-growth, selfcontentment, and individual and social fulfilment. Our results showed that individuals' subjective experiences and meaning-making processes frame the way in which they are able to manage health. Moreover, our data provide an insight into the complex and challenging nature of older people's experiences of engagement in health promotion conducts. The experiential trajectories that emerged from our study revealed the importance of supporting older citizens' positive sense-making process to improve their ageing and health promotion. For instance, participants in a 'locked position' reported the protective role of positive emotions on their physical and mental health over time by confirming evidences from positive psychology literature. ${ }^{35-38}$ Considering the emotional conflict between being aware of the importance of assuming healthier conducts and the difficulty in translating this knowledge to concrete behaviours of health prevention and health promotion, which characterise the 'awakening position', behavioural education may be useful for these older citizens, as it can foster a greater psychological integration between 'actions and thoughts'. For instance, planning daily habits, setting goals and activating social support are all useful strategies for improving older citizens' engagement in health promotion. In this direction, technologies might be particularly useful for planning healthy behaviours and connecting with other members of the community with whom older citizens could share health practices.

Older citizens in the 'climbing profile' may maintain their engagement in health promotion by sustaining their mental and psychological tenure, for instance, with exercises or counselling aimed to foster their selfefficacy, self-empowerment, cognitive reinforcement, self-worth and purpose in life. These factors are indeed crucial for "optimising aging well and enhancing the quality of later life, enabling older people to feel confident in living with wider benefits to society" (ref. 39, p. 9). Older citizens' ability to maintain meaningful social relationships is also important in the 'climbing position' and needs to be supported because playing an active social role in the community was conceived as a way to have a purpose in life and to be "part of something bigger', which can give sense to life and death.

These results suggest that interventions aimed at promoting health in ageing should consider the subjective experiences of older citizens and the elements that may sustain or hinder their engagement in healthy conducts. In particular, our results emphasised the importance of favouring the emergence of older citizens' positive psychological attitudes towards health and ageing (eg, positive emotions, motivation and goal setting, fulfilment and self-improvement) to improve their engagement in health promotion. Currently, different studies and interventions are available to confirm the effective value of working on such psychological states to foster health 
behaviour change. ${ }^{40-46}$ Most studies considered populations with chronic conditions; thus, they mainly aimed to improve medication adherence and disease management $^{40} \quad 42-45$ and did not specifically target older samples $^{40}{ }^{42-44}$ and health promotion initiatives. The few studies carried out with older populations mostly aimed to enhance the mental well-being and quality of life. ${ }^{37} 3845$

\section{Study limits and future research}

The findings of this study contribute to deepening the subjective experience of older citizens' health promotion by underlining the elements that may sustain or inhibit their engagement in such conduct. The study focused deliberately on exploring how older participants individually contribute to their engagement in their health promotion. The social context was only marginally explored, although it can play an important role in individual health engagement trajectories. ${ }^{47}$ Surely social health promotion initiatives should be grounded in expectations and needs of citizens, but a balance between individual needs and common needs has to be considered when designing and delivering such initiatives. $^{47}$

Furthermore, the study reported on the reflections of participants on their health actions. Thus, although the method adopted allowed us to understand implicit meanings related to individual experiences by studying the language used by participants, techniques to give voice to the unconscious aspects that can potentially influence an individual's behaviours and actions were not adopted.

A limitation of our study concerns the characteristics of our sample. Older adults living in other parts of Italy (and in other countries) may have different perceptions and experiences. However, through the analysis of the experiences that the participants recounted, only themes that all participants endorsed were extracted with an aim to include only the most common beliefs. The inclusion of participants younger than 75 years of age at the time of the interview was deliberate in order to explore experiences of and needs towards health promotion initiatives of a population that may best benefit from health prevention and promotion initiatives. We are aware that health promotion experiences and needs would change in an older segment of the population. Further studies are needed to explore the specific needs and experiences of older populations. Furthermore, the choice of the ethnoscience method required that participants enrolled in the study had sufficient linguistic and reflexive skills to complete the Q-sorting tasks. Further explorations are needed to assess the health promotion experiences and needs of citizens with different levels of educational and cognitive skills.

Finally, further studies are needed to investigate factors (ie, demographical, clinical, personality, cultural) that might influence the process of older citizens' engagement in health promotion. We are aware of these limits of the study and for this reason, we plan to conduct a wider quantitative study on a larger sample to further verify our results, to collect further information of the experiences of older people's engagement in health promotion, and to verify the variables (sociological, demographical and psychological) that may predict such experiences. Future research should seek to support ecological, feasible and effective interventions with an aim to foster older people's engagement in health promotion. Similar results would guide the development of interventions that would successfully involve older citizens in healthy ageing conducts.

Acknowledgements The study was funded by Catholic University, Faculty of Psychology (Project D.3.2 2012 Crescere da Anziani: Attivare risorse per stili di vita sostenibili, scientific responsible: prof. Alessandro Antonietti). The authors express their gratitude to Dario Bussolin and Alessandra Pagani for their help with the applied parts of the research. They are also particularly thankful to all the participants who made this research possible.

Contributors JM conducted interviews and all analyses, wrote the first draft of the manuscript and rewrote new drafts based on input from co-authors. GG designed the research project, planned the analyses and provided input and revision of manuscript drafts. All authors read and approved the final manuscript.

Funding All authors have completed the ICMJE uniform disclosure form at http://www.icmje.org/coi_disclosure.pdf and declare that all authors had financial support from Catholic University (Department of Psychology Project D.3.2 2012 Crescere da Anziani: Attivare risorse per stili di vita sostenibili, scientific responsible: prof. Alessandro Antonietti) for the submitted work.

Competing interests None declared.

Patient consent Obtained.

Ethics approval The Catholic University of Milan Ethics Review Board approved the study.

Provenance and peer review Not commissioned; externally peer reviewed.

Data sharing statement Original quotes and audio data of interviews are available on request by emailing the corresponding author. The presented data were anonymised and the risk of identification is low.

Open Access This is an Open Access article distributed in accordance with the Creative Commons Attribution Non Commercial (CC BY-NC 4.0) license, which permits others to distribute, remix, adapt, build upon this work noncommercially, and license their derivative works on different terms, provided the original work is properly cited and the use is non-commercial. See: http:// creativecommons.org/licenses/by-nc/4.0/

\section{REFERENCES}

1. Lutz W, Sanderson W, Scherbov S. The coming acceleration of global population aging. Nature 2008;451:716-19.

2. Istituto Nazionale di Statistica. Annuario Statistico Italiano 2013. http://www.istat.it/it/archivio/107568

3. World Health Organisation. Active aging: a policy framework. Geneva; World Health Organisation, 2002.

4. Hibbard JH, Greene J. What the evidence shows about patient activation: better health outcomes and care experiences; fewer data on costs. Health Aff 2013;32:207-14.

5. Rosenstock I. Historical origins of the health belief model. Health Educ Behav 1974;2:328-35.

6. Janz NK, Marshall HB. The health belief model: a decade later. Health Educ Behav 1984;11:1-47.

7. Becker MH, Maiman LA, Kirscht JP, et al. The Health Belief Model and prediction of dietary compliance: a field experiment. $J$ Health Soc Behav 1977;18:348-66.

8. Prochaska JO, Velicer WF. The transtheoretical model of health behavior change. Am J Health Promot 1997;12:38-48. 
9. Bandura A. Health promotion from the perspective of social cognitive theory. Psychol Health 1998;13:623-49.

10. Ajzen I. The theory of planned behavior. Organ Behav Hum Decis Process 1991:50:179-211.

11. Kreuter MW, Lukwago SN, Bucholtz RD, et al. Achieving cultural appropriateness in health promotion programs: targeted and tailored approaches. Health Educ Behav 2003;30:133-46.

12. Halfon N, Hochstein M. Life course health development: an integrated framework for developing health, policy, and research Milbank Q 2002;80:433-79, iii.

13. Yasuda N, Zimmerman SI, Hawkes W, et al. Relation of social network characteristics to 5 -year mortality among young-old versus old-old White women in an urban community. Am J Epidemiol 1997;145:516-23.

14. Crawford R. A cultural account of 'health': control, release, and the social body. In: McKinlay JB, ed. Health and wellbeing. UK: Macmillan Education, 1993:133-43.

15. Hansen-Kyle L. A concept analysis of healthy aging. Nurs Forum 2005;40:45-57.

16. Peel NM, Bartlett HP, McClure RJ. Healthy aging: how is it defined and measured? Austral J Aging 2004;23:115-19.

17. Menichetti J, Cipresso P, Bussolin D, et al. Engaging older people in active and healthy lifestyles: a systematic review. Aging Soc 2015;2:8.

18. European Commission. The 2012 Ageing Report: economic and budgetary projections for the EU27 Member States (2010-2060). 2012. http://ec.europa.eu/economy finance/publications/european economy/2012/pdf/ee-2012-2_en.pdf (accessed 21 Jul 2015).

19. Christensen U, Støvring N, Schultz-Larsen K, et al. Functional ability at age 75: is there an impact of physical inactivity from middle age to early old age? Scand J Med Sci Sports 2006;16:245-51.

20. EuroHealthNet. 2012- Health and active ageing. http://www. healthyageing.eu/sites/www.healthyageing.eu/files/featured/Healthy \%20and\%20Active\%20Ageing.pdf

21. Espinel PT, King L, Hector D. Obesity and chronic disease prevention among older adults (55-74 years): an evidence overview and framework to inform policy and practice. Sydney; Physical Activity Nutrition \& Obesity Research Group, 2014. http://sydney. edu.au/medicine/public-health/panorg/

22. Leininger M. Ethnoscience method and componential analysis. In: Leininger M, ed. Qualitative research methods in nursing. London: Grune \& Stratton, 1985:237-49.

23. Merriam SB. Qualitative research: a guide to design and implementation. John Wiley \& Sons, 2014.

24. Brown SR. Q methodology and qualitative research. Qual Health Res 1996;6:561-7.

25. Brown SR, Durning DW, Selden S. Q methodology. Public Adm Public Policy 1999;71:599-638.

26. Van Exel J, De Graaf G. Q methodology: a sneak preview. 2005. http://www.jobvanexel.nl

27. Olson $\mathrm{K}$, Zimka O, Stein $\mathrm{E}$. The nature of fatigue in chronic fatigue syndrome. Qual Health Res 2015; 25:1410-22.

28. Palys T. Purposive sampling. In: Given LM, ed. The Sage encyclopedia of qualitative research methods. Vol. 2 Los Angeles: Sage, 2008:697-8.

29. Sadler GR, Lee HC, Lim RSH, et al. Recruitment of hard-to-reach population subgroups via adaptations of the snowball sampling strategy. Nurs Health Sci 2010;12:369-74.
30. Morse JM. Strategies for sampling. In: Morse JM, ed. Qualitative nursing research: a contemporary dialogue. Newbury Park, California: Sage, 1991:127-45.

31. Noy C. Sampling knowledge: the hermeneutics of snowball sampling in qualitative research. Int $J$ Soc Res Meth 2008;11 327-44.

32. Braun V, Clarke V. Using thematic analysis in psychology. Qual Res Psychol 2006;3:77-101.

33. Van Nes F, Abma T, Jonsson $\mathrm{H}$, et al. Language differences in qualitative research: is meaning lost in translation? Eur $J$ Ageing 2010;7:313-16.

34. Reichstadt J, Sengupta G, Depp CA, et al. Older adults' perspectives on successful aging: qualitative interviews. $A m \mathrm{~J}$ Geriatric Psychiatry 2010;18:567-75.

35. Dainese SM, Allemand M, Ribeiro N, et al. Protective factors in midlife: how do people stay healthy? GeroPsych 2011; 24:19.

36. Ong AD, Bergeman CS, Bisconti TL, et al. Psychological resilience, positive emotions, and successful adaptation to stress in later life. J Pers Soc Psychol 2006;91:730.

37. Ramírez E, Ortega AR, Chamorro A, et al. A program of positive intervention in the elderly: memories, gratitude and forgiveness. Aging Ment Health 2014;18:463-70.

38. Ho HC, Yeung DY, Kwok SY. Development and evaluation of the positive psychology intervention for older adults. J Posit Psychol 2014:9:187-97.

39. Bowling A, Iliffe S. Psychological approach to successful ageing predicts future quality of life in older adults. Health Qual Life Outcomes 2011:9:13.

40. Cohn MA, Pietrucha ME, Saslow LR, et al. An online positive affect skills intervention reduces depression in adults with type 2 diabetes. $J$ Posit Psychol 2014;9:523-34.

41. Fredrickson BL. Cultivating positive emotions to optimize health and well-being. Prev Treat 2000;3:1a. http://www.unc.edu/peplab/ publications/Fredrickson_2000_2000 Prev\&Trmt.pdf

42. Mancuso CA, Choi TN, Westermann $\mathrm{H}$, et al. Increasing physical activity in patients with asthma through positive affect and self-affirmation: a randomized trial. Arch Intern Med 2012;172:337-43.

43. Ogedegbe GO, Boutin-Foster C, Wells MT, et al. A randomized controlled trial of positive-affect intervention and medication adherence in hypertensive African Americans. Arch Intern Med 2012;172:322-6.

44. Peterson JC, Charlson ME, Hoffman Z, et al. Randomized controlled trial of positive affect induction to promote physical activity after percutaneous coronary intervention. Arch Intern Med 2012;172:329-36.

45. Huffman JC, Mastromauro CA, Boehm JK, et al. Development of a positive psychology intervention for patients with acute cardiovascular disease. Heart Int 2011;6:2

46. Proyer RT, Gander F, Wellenzohn S, et al. Positive psychology interventions in people aged $50-79$ years: long-term effects of placebo-controlled online interventions on well-being and depression. Aging Ment Health 2014;18:997-1005.

47. Callahan D, Koenig B, Minkler M. Promoting health and preventing disease: ethical demands and social challenges. Int $Q$ Community Health Educ 1998;18:163-80. 